\title{
Editorial
}

\section{Novel Concepts in the Management of Colorectal Cancer}

\author{
Thomas Seufferlein $^{a}$ Jürgen Weitz ${ }^{b}$

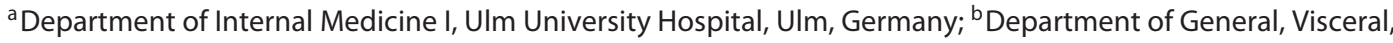 \\ Thoracic and Vascular Surgery, University Hospital Carl Gustav Carus, TU Dresden, Dresden, Germany
}

The current issue of Visceral Medicine focuses on colorectal cancer. Despite intense screening efforts, colorectal cancer still belongs to the most frequent cancers in both males and females in the EU. Particularly in rectal cancer there have been major developments in the surgical techniques over the last years that have led to a substantial reduction in local disease recurrence. Recently, robotic surgery has emerged as a novel technique that may help further improve the outcome for patients with colorectal cancer. However, we have seen major improvements not only in colorectal cancer surgery, but also in the molecular understanding of the disease and subsequently in the development of compounds that target specific molecular pathways mainly in defined subgroups of cancers. This issue presents the current evidence and also points out future directions of research both in the surgical as well as systemic treatment of colorectal cancer.

Bogner et al. [1] give an overview of modern developments in rectal cancer surgery and the role of surgery in a multidisciplinary treatment concept for rectal cancer.
Shah et al. [2] present the current data on minimally invasive and robotic surgery for colorectal cancer. They point out the potential advantages but also the limitations of these techniques.

Seufferlein et al. [3] give an overview of the molecular setup of colorectal cancer and its therapeutic consequences. They also discuss the role of advanced molecular diagnostics for subtyping and treating metastatic colorectal cancer.

The current issue of Visceral Medicine with a focus on colorectal cancer hopefully provides you with clinically useful information for your daily practice.

\begin{tabular}{|c|c|}
\hline References & $\begin{array}{l}1 \text { Bogner A, Kirchberg J, Weitz J, Fritzmann J. } \\
\text { State of the art - rectal cancer surgery. Visc } \\
\text { Med. DOI: } 10.1159 / 000501133 \text {. } \\
2 \text { Shah MF, Nasir I, Parvaiz A. Robotic Surgery } \\
\text { for Colorectal Cancer. Visc Med. DOI: } \\
10.1159 / 000500785 \text {. } \\
3 \text { Seufferlein T, Simões C, Kude F, Ettrich TJ. } \\
\text { Molecular approaches to metastatic colorec- } \\
\text { tal cancer- better diagnosis - better treat- } \\
\text { ment? Visc Med. DOI: } 10.1159 / 000500617 \text {. }\end{array}$ \\
\hline
\end{tabular}

Prof. Dr. med. Thomas Seufferlein

Department of Internal Medicine I, Ulm University Hospital

Albert-Einstein-Allee 23

DE-89081 Ulm (Germany)

E-Mail thomas.seufferlein@uniklinik-ulm.de 